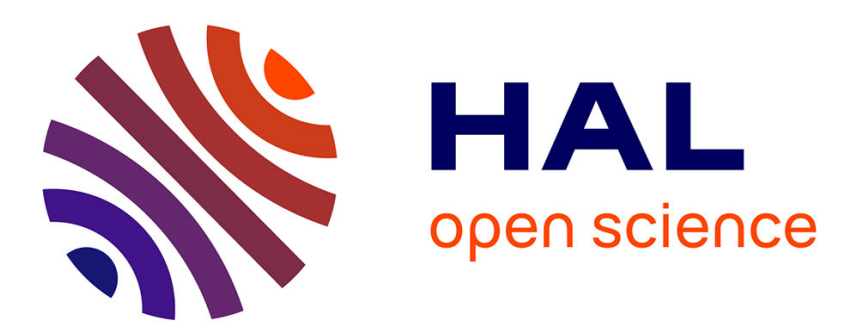

\title{
Explicit solvation effects on the conventional resonance model for protonated imine, carbonyl, and thiocarbonyl compounds
}

Benoît Braïda, Philippe C. Hiberty

\section{- To cite this version:}

Benoît Braïda, Philippe C. Hiberty. Explicit solvation effects on the conventional resonance model for protonated imine, carbonyl, and thiocarbonyl compounds. International Journal of Quantum Chemistry, 2010, 110 (3), pp.571-577. 10.1002/qua.22095 . hal-01627704

\section{HAL Id: hal-01627704 https://hal.science/hal-01627704}

Submitted on 21 Nov 2017

HAL is a multi-disciplinary open access archive for the deposit and dissemination of scientific research documents, whether they are published or not. The documents may come from teaching and research institutions in France or abroad, or from public or private research centers.
L'archive ouverte pluridisciplinaire HAL, est destinée au dépôt et à la diffusion de documents scientifiques de niveau recherche, publiés ou non, émanant des établissements d'enseignement et de recherche français ou étrangers, des laboratoires publics ou privés. 


\title{
Explicit Solvation Effects on the Conventional Resonance Model for Protonated Imine, Carbonyl, and Thiocarbonyl Compounds
}

\author{
BENOÎT BRAÏDA, ${ }^{1,2}$ PHILIPPE C. HIBERTY ${ }^{2,3}$ \\ ${ }^{1}$ UPMC Université Paris 06, UMR 7616, Laboratoire de Chimie Théorique, Case courrier 137, \\ 4 place Jussieu, 75252 Paris, France \\ ${ }^{2}$ CNRS Centre National de la Recherche Scientifique \\ ${ }^{3}$ Laboratoire de Chimie Physique, Bât 349, Université de Paris-Sud, CNRS UMR 8000, \\ 91405 Orsay, France
}

\begin{abstract}
The conventional resonance model describes carbonyls, imines, and thiocarbonyls, as well as their protonated analogues, by a superposition of two valence bond structures. Ab initio Breathing-Orbital Valence Bond computations on formaldehyde, formimine, and thioformaldehyde as well as their protonated forms are performed to directly quantify the weights of their valence bond structures. Following a gas phase study that showed that protonation significantly increases the weight of the carbenic form relative to the $\pi$ polar-covalent bonded form (Braida, et al., Org Lett, $2008,10,1951)$, the present work estimates the influence of a polar protic solvent, modelized by water. Solvation effects are modeled explicitly by performing VB calculations on supersystems made of the organic substrate surrounded by four water molecules. It is shown that protonation significantly increases the polarity of the $\mathrm{C}-\mathrm{X} \pi$ bond in all three cases $(\mathrm{X}=\mathrm{O}, \mathrm{NH}, \mathrm{S})$ in solvated phase, in line with the known acceleration of nucleophilic additions on these compounds by acidic catalysis. Moreover, solvation significantly enhances the polarity of the C-X $\pi$ bond in the protonated forms of formaldehyde and thioformaldehyde, but has practically no effect on the C-X $\pi$ bond of protonated formimine. () 2009 Wiley Periodicals, Inc. Int J Quantum Chem 110: 571-577, 2010
\end{abstract}

Key words: resonance model; valence bond theory; BOVB; solvent effect; carbonyl; thiocarbonyl; imines; nucleophilic reactions 


\section{Introduction}

I $\mathrm{t}$ is common chemical knowledge that nucleophilic reactions on carbonyl compounds are considerably fastened by acidic catalysis. A similar rate enhancement is also observed for imine and thiocarbonyl compounds. In the framework of Frontier Orbital Theory [1], it is argued that protonation has the effect of lowering the lowest unoccupied molecular orbital (LUMO), actually a $\pi$-type antibonding $\mathrm{MO}$, thus favoring the stabilizing interaction with the highest occupied $\mathrm{MO}$ of the nucleophile. On the other hand, the conventional resonance model proposes an explanation based on Scheme 1, in which protonated carbonyls, imines, and thiocarbonyls are represented as a superposition of two mesomeric structures, one $\pi$ polar-covalent (I) and the other of carbenium type (II).

More precisely, Structure I in Scheme 1 is defined as a polar $\pi \mathrm{C}-\mathrm{O}$ bond exactly similar to that of the unprotonated compound, that is, having the same polarity, whereas the $\pi$-electron pair in Structure II is entirely localized on the $\mathrm{X}$ atom. According to this scheme, $\mathrm{R}_{2} \mathrm{C}=\mathrm{X}(\mathrm{X}=\mathrm{O}, \mathrm{NH}, \mathrm{S})$ would lose some of its double bond character upon protonation, to the benefit of the carbenic form (II). Just how large is the weight of II relative to I has attracted the attention of experimentalists as well as theoreticians for several decades, especially in the carbonyl case [2-10].

Various techniques have been used. On the experimental side, ${ }^{17} \mathrm{O}-\mathrm{NMR}$ shifts have been used as indicators of carbonyl-oxygen $\pi$-bond order [2-5]. On the theoretical side, several criteria have been used, ranging from bond length considerations [6-8] to calculated net charges [6, 8-10], according to various definitions of electron density partitioning.

Very recently, we addressed the problem in a direct way by calculating the weights of I and II in the protonated compounds by means of ab initio valence bond (VB) calculations, using the high quality breathing orbital valence bond (BOVB) method
[11]. The results of the calculation for the parent compounds $\mathrm{H}_{2} \mathrm{C}=\mathrm{X}(\mathrm{X}=\mathrm{O}, \mathrm{NH}, \mathrm{SH})$ and its protonated form, recalled in Table III, clearly supported the conventional resonance model, by yielding a $28 \%$ weight for the carbenium form in protonated formaldehyde and $19 \%$ in both protonated formamine and thioformaldehyde. The effects of $\pi$-donating substituents were also investigated, and were shown to further increase the weight of the carbonic structure II relative to the parent protonated compound. Now an important point to keep in mind is that all the above theoretical results [6-11] refer to gas phase conditions, whereas acidcatalyzed nucleophilic reactions take place in protic solvents, mostly water.

In our VB study [11], we roughly estimated solvent effects by using a standard solvation model, the polarized continuum model (PCM),[12] and tentatively concluded that solvation does not fundamentally change the gas phase structural weigths. However, the latter proposal could not be considered as firmly established, as the PCM model does not take into account the explicit interactions between the substrate and the solvent molecules of the first solvation shell. Thus, to provide a more reliable estimation of solvent effects, the aim of the present work is to readdress the problem by performing a VB study of explicitly solvated neutral and protonated fomaldehyde, formamine, and thioformaldehyde, using a more realistic solvation model. In the present model, the substrate effectively interacts with explicit water molecules, to form a supersystem that is imbedded in a polarized continuum that figures out the outer solvation shells.

\section{Theoretical Methods and Strategy}

\section{GEOMETRY OPTIMIZATIONS FOR THE SUBSTRATE-SOLVENT SUPERSYSTEMS}

The geometry optimizations were performed at the level of density functional theory (DFT), using
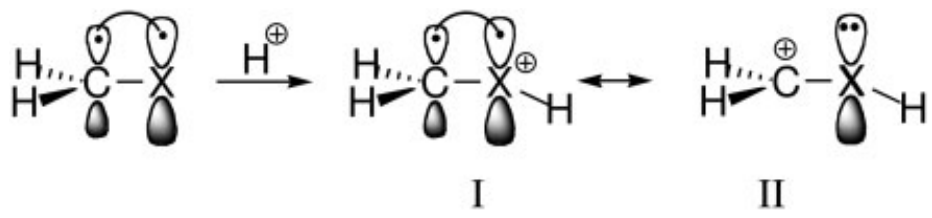

$$
(\mathrm{X}=\mathrm{O}, \mathrm{NH}, \mathrm{S})
$$

SCHEME 1. The conventional resonance model for formaldehyde, formamide and thioformaldehyde. 
the standard B3LYP hybrid functional. The standard 6-31G(d) basis set, of double-zeta + polarization quality, was used throughout. All calculations are done within the CPCM polarizable conductor model framework [13] with water as the solvent, at a temperature of $300 \mathrm{~K}$.

The basic strategy for building the final supersystem, made of the substrate surrounded by a small number of water molecules, is the following. We calculate geometry-optimized supersystems of increasing sizes, that is, involving one, two, three, and more water molecules. At the $n$th step, we compute the variation in substrate free solvation energy due to the incorporation of an $n$th explicit water molecule $\Delta \Delta G_{n}^{\text {solv }}$ using Eq. (1) below, where $E^{\mathrm{CPCM}}$ corresponds to the CPCM free energies in solution, and Complex ${ }_{n}$ designates a supersystem of $n$ water molecules surrounding the organic substrate.

$$
\begin{array}{r}
\Delta \Delta G_{n}^{\text {solv }}=E^{\mathrm{CPCM}}\left(\text { Complex }_{\_n}\right)-E^{\mathrm{CPCM}}\left(\text { Complex }_{-n-1}\right) \\
-E^{\mathrm{CPCM}}\left(\mathrm{H}_{2} \mathrm{O}\right)
\end{array}
$$

The process is stopped when the stabilization $\Delta \Delta G_{n}^{\text {solv }}$ is deemed negligible (less than $1 \mathrm{kcal} / \mathrm{mol}$ ). Only the complexes where all water molecules directly interact with the organic substrate are selected, that is, complexes involving water chains are discarded. Applying this strategy led to three water molecules for protonated formaldehyde and for neutral thioformaldehyde, and to four water molecules for all other compounds. Then, for the sake of consistency, we retained the largest number of water molecules (i.e., four) for all solvated compounds.

\section{THE BREATHING-ORBITAL VALENCE BOND METHOD}

In VB theory [14, 15], a many-electron wave function is expressed in terms of VB functions $\Phi_{K}$,

$$
\Psi=\sum_{K} C_{K} \Phi_{K}
$$

where each $\Phi_{K}$ corresponds to a traditional VB structure, purely covalent or ionic. In the present work, the VB wave functions are calculated by the "breathing-orbital valence bond method" (BOVB) [16], a method that has been extensively tested for its reliability and high accuracy [16c].

The coefficients and orbitals of the VB structures are optimized simultaneously, so as to minimize the total energy of the multistructure wave func- tion. During the optimization process, each VB structure is allowed to possess its specific set of orbitals, different from one VB structure to the other. In this manner, the orbitals can fluctuate in size and shape so as to fit the instantaneous charges of the atoms on which these orbitals are located. This specificity of the BOVB method ensures its accuracy by bringing some dynamic correlation to the wave function, without increasing the number of VB configurations. In this work, only the orbital on the substrate are "breathing," whereas the orbitals of the water molecules remain the same in the different VB structures. The $\pi$ system is treated at the VB level, whereas the other electrons, including those of the $\mathrm{H}_{2} \mathrm{O}$ molecules, are in delocalized molecular orbitals. However, all orbitals are optimized, so that the influence of the $\sigma$ bonds and that of the solvent molecules on the $\pi$ system are accounted for. As is usually done, the importance of each VB structure $\Phi_{K}$ is characterized by its $\ll$ weight $\gg W_{K}$, that is extracted from the coefficients, according to the standard Chirgin-Coulson formula [17], Eq. (3):

$$
W_{K}=C_{K}^{2}+\sum_{L \neq K} C_{K} C_{L}\left\langle\Phi_{K} \mid \Phi_{L}\right\rangle
$$

The VB structures that are considered in the present work are displayed in Figure 1. At variance with previous VB computations [18], the $\pi$ atomic orbitals (AO) that are used to define the VB structures are strictly localized on a single atom (C or $\mathrm{X})$. This way, the distribution of electrons in the $\pi$ space is very clear. For example, VB structures $\mathbf{1}$ and $\mathbf{1}_{\mathrm{P}}$ that display a purely covalent $\pi$ bond (noted $\bullet-\bullet$ ), have one $\pi$ electron on $\mathrm{C}$ and another on $\mathrm{X}$. VB structures having inverse polarity, of the type $\mathrm{H}_{2} \mathrm{C}^{-}-\mathrm{O}^{+}$or $\mathrm{H}_{2} \mathrm{C}^{-}-\mathrm{O}^{2+} \mathrm{H}$, are discarded for the sake of simplicity. All VB calculations were performed with the XMVB ab initio valence bond program of the Xiamen group [19]. The B3LYP/CPCM calculations were performed with the Gaussian 03 package of programs [20].
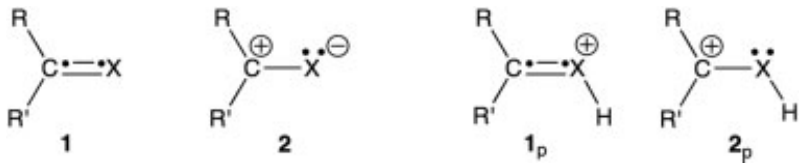

FIGURE 1. Valence bond structures for the unprotonated species (1-2) and for the protonated species $\left(\mathbf{1}_{\mathrm{P}^{-}}\right.$ 2). 

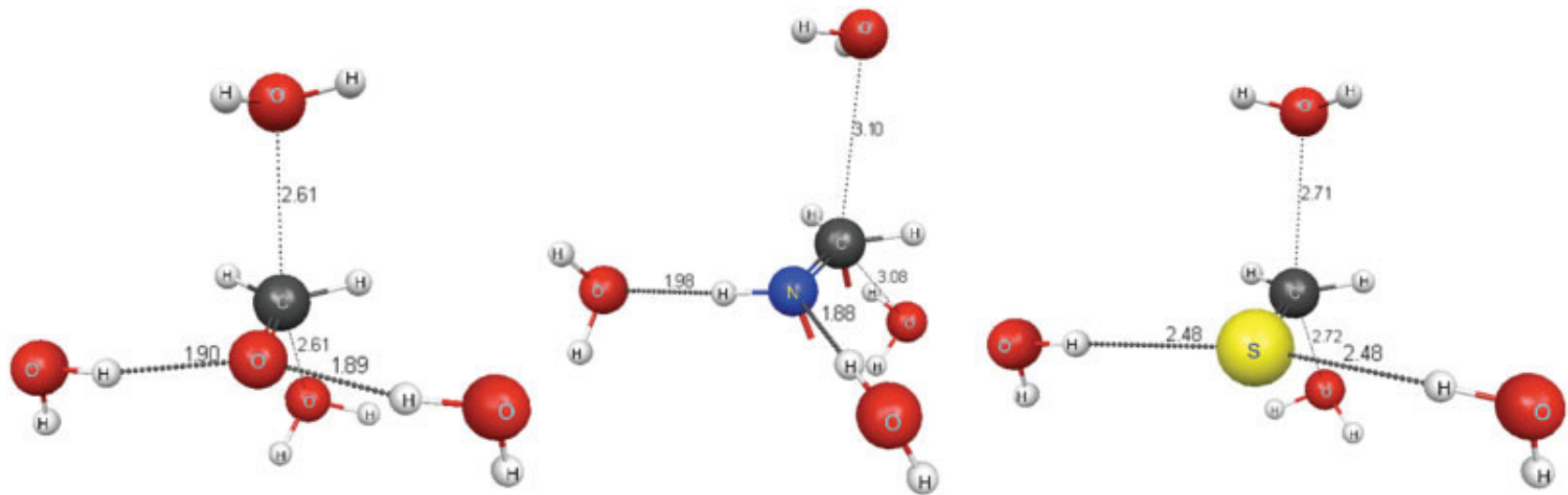

FIGURE 2. Optimized geometries of the neutral formaldehyde, formimine, and thioformaldehyde in water. [Color figure can be viewed in the online issue, which is available at www.interscience.wiley.com.]

\section{Results}

\section{GEOMETRIES OF THE SUPERSYSTEMS AND SOLVATION FREE ENERGIES}

The optimized geometries for the solvated neutral formaldehyde, formimine, and thioformaldehyde are displayed in Figure 2. In all cases, the $X$ fragment $(X=O, N H, S)$ is surrounded by two water molecules which form hydrogen bonds in the molecular plane of the substrate. On the other hand, the carbon center is flanked by two further water molecules, on both sides of the molecular plane. The shortest distances between the carbon center and the solvent molecules are found for formaldehyde, in agreement with the larger polarity of the $\mathrm{C}-\mathrm{X} \pi$ bond in this molecule relative to the other two. The large carbon-water distance in formimine, more than $3 \AA$, reflects the fact the two water molecules hardly stabilize the carbon center, as mentioned in the theoretical section.

The geometries of the solvated protonated compounds are displayed in Figure 3. As can be seen, all the solvent-substrate distances are shorter than the corresponding distances in the neutral compounds. This is a sign of a strongest solvent-substrate interaction, which reflects the fact that protonation has the effect of increasing the polarity of the $\mathrm{C}-\mathrm{X}$ linkage, as can be seen from the significant weight of the carbenic form $\mathbf{2}_{\mathbf{P}}$ in all compounds in the gas phase (see Table I).

\section{WEIGHTS OF THE VB STRUCTURES}

The weights of the VB structures for the species in the gas phase have been calculated in our previ-
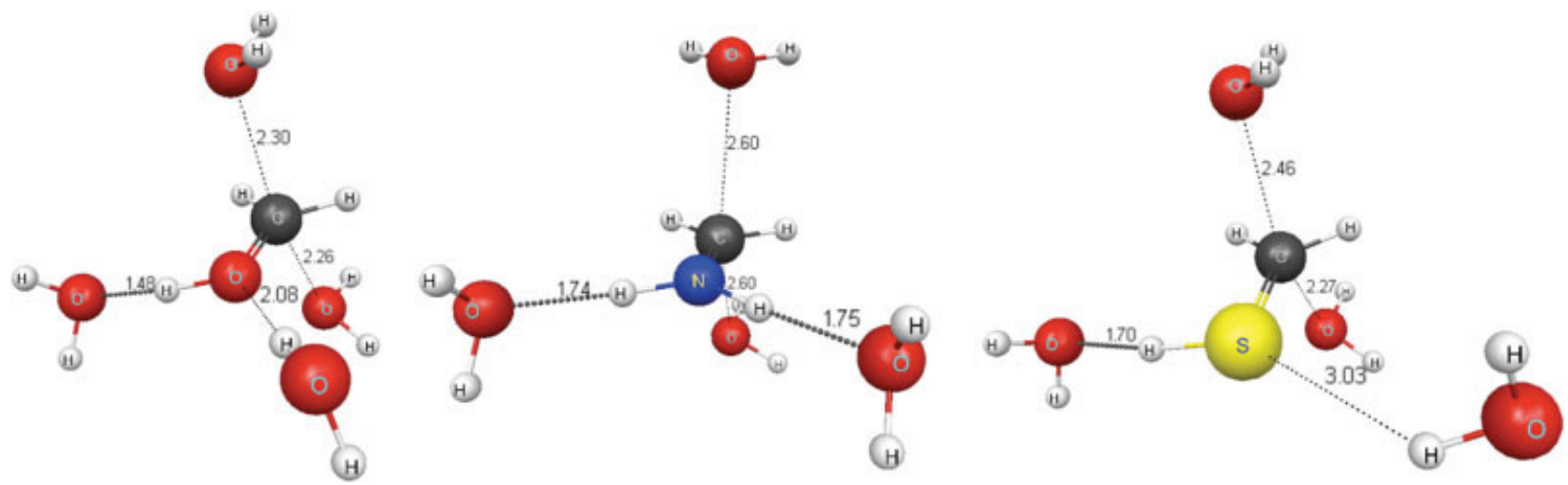

FIGURE 3. Optimized geometries of the protonated formaldehyde, formimine, and thioformaldehyde in water. [Color figure can be viewed in the online issue, which is available at www.interscience.wiley.com.] 
TABLE I

Weights (in \%) of VB structures for formaldehyde, formimine, thioformaldehyde, and their protonated species, in the gas phase. Last column: polarity enchancement (in \%) due to protonation, as defined through equation (4).

\begin{tabular}{|c|c|c|c|c|c|}
\hline \multirow[b]{2}{*}{$X$} & \multicolumn{2}{|c|}{ Carbonyl, imine, thiocarbonyl } & \multicolumn{3}{|c|}{ Protonated species } \\
\hline & $H_{2} \mathrm{C}=X \omega(\mathbf{1})$ & $\begin{array}{c}\mathrm{H}_{2} \mathrm{C}_{\omega(2)}^{+}-\mathrm{X}^{-} \\
\end{array}$ & $\begin{array}{c}\mathrm{H}_{2} \mathrm{C}=\mathrm{X}^{+} \mathrm{H} \\
\omega\left(\mathbf{1}_{\mathbf{P}}\right)\end{array}$ & $\begin{array}{c}\mathrm{H}_{2} \mathrm{C}^{+}-\mathrm{XH} \\
\omega\left(\mathbf{2}_{\mathbf{p}}\right)\end{array}$ & $\begin{array}{l}\text { Polarity enhancement (p.e.) } \\
\qquad\left(\frac{\omega_{2 p}}{\omega_{2}}-1\right) \times 100 \\
\end{array}$ \\
\hline 0 & 68.0 & 32.0 & 48.8 & 51.2 & +60.0 \\
\hline $\mathrm{NH}$ & 73.4 & 26.6 & 59.3 & 40.7 & +53.0 \\
\hline$S$ & 75.7 & 24.3 & 61.5 & 38.5 & +58.4 \\
\hline
\end{tabular}

ous study [11] and are recalled in Table I, columns 1 and 2. It is seen that the $\pi$ bond of $\mathrm{H}_{2} \mathrm{C}=\mathrm{X}$ involves a major purely covalent component 1 combined with a minor ionic component 2 , the ionic weight characterizing the polarity of the familiar polar-covalent bond $\mathrm{C}=\mathrm{X}$.

The same analysis performed on the protonated species (structures $\mathbf{1}_{\mathbf{P}}$ and $\mathbf{2}_{\mathbf{P}}$, columns 3 and 4 ) shows that protonation affects the CX $\pi$ bond in a significant way, diminishing the weight of the covalent component $\mathbf{1}_{\mathbf{P}}$ and increasing that of the carbenic component $\mathbf{2}_{\mathrm{p}}$, which can be interpreted as a participation of II in the resonating Scheme 1. In the last column of Table I, the polarity enhancement due to protonation is displayed, as defined through the Eq. (4) below:

$$
\text { p.e. }(\%)=\left(\frac{\omega_{2 p}}{\omega_{2}}-1\right) \times 100
$$

The polarity enhancement is large in all cases, amounting to $53-60 \%$.

The weights of the VB structures for the solvated species are displayed in Table II. Let us consider the neutral compounds first (columns 1 and 2). By comparing the weights of structures $\mathbf{1}$ and $\mathbf{2}$ in Table II to the weights of the same structures in Table I, it appears that solvation increases the weight of the carbenic form 2 relative to the covalent form $\mathbf{1}$ in all neutral compounds. In other words, solvation increases the polarity of the $\mathrm{C}-\mathrm{X} \pi$ bond. The weight enhancement of 2 when going from gas phase to solution, as defined by: $\left(\omega_{2}^{\text {solution }} / \omega_{2}^{\text {gas phase }}-1\right) \times$ 100 is large in formaldehyde $(+30 \%)$, even larger in thiformaldehyde $(+37 \%)$, but very small in formimine $(+3 \%)$, in harmony with the weak solvation effect at the carbon site of this latter compound.

Turning to the protonated species in the solvated phase, it can be seen that the weight of the protonated carbenic form, $\mathbf{2}_{\mathbf{P}}$, is always increased relative to the unprotonated carbenic form 2 (compare column 4 to column 2 in Table II). This indicates that protonation increases the carbenic character of all three compounds in water, as was found in the gas phase. The polarity enhancement due to protonation is large in the three molecules under study, as can be appreciated by using Eq. (4). This ratio is in the range $45-61 \%$ in solvated phase, quite compa-

TABLE II

Weights of VB structures for formaldehyde, formimine, thioformaldehyde, and their protonated species, explicity solvated by water molecules. Last column: polarity enchancement (in \%) due to protonation, as defined through equation (5).

\begin{tabular}{|c|c|c|c|c|c|}
\hline \multirow[b]{2}{*}{$x$} & \multicolumn{2}{|c|}{ Carbonyl, imine, thiocarbonyl } & \multicolumn{3}{|c|}{ Protonated species } \\
\hline & $H_{2} \mathrm{C}=X \omega(\mathbf{1})$ & $\begin{array}{c}\mathrm{H}_{2} \mathrm{C}^{+}-\mathrm{X}^{-} \\
\omega(2)\end{array}$ & $\begin{array}{c}\mathrm{H}_{2} \mathrm{C}=\mathrm{X}^{+} \mathrm{H} \\
\omega\left(\mathbf{1}_{\mathbf{p}}\right)\end{array}$ & $\begin{array}{c}\mathrm{H}_{2} \mathrm{C}^{+}-\mathrm{XH} \\
\omega\left(\mathbf{2}_{\mathbf{p}}\right)\end{array}$ & $\begin{array}{l}\text { Polarity enhancement (p.e.) } \\
\qquad\left(\frac{\omega_{2 p}}{\omega_{2}}-1\right) \times 100\end{array}$ \\
\hline 0 & 58.0 & 41.7 & 39.7 & 60.3 & +44.6 \\
\hline $\mathrm{NH}$ & 72.7 & 27.3 & 57.0 & 43.0 & +57.5 \\
\hline $\mathrm{s}$ & 66.8 & 33.2 & 46.4 & 53.6 & +61.4 \\
\hline
\end{tabular}


rable to the values $53-60 \%$ in the gas phase. This result is in line with the experimental fact that nucleophilic additions on carbonyl, thiocarbonyl as well as on imine compounds are all considerably fastened by acidic catalysis, with a similar rate enhancement [1]. The polarity enhancement appears to be slightly larger in the solvated phase for formimine and thioformaldehyde, whereas it is smaller for formaldehyde in solvated phase $(44.6 \%)$ when compared with gas phase (60.0\%). At variance with the two other species, neutral formaldehyde is already very polarized in solvated phase, so protonation does not increase the polarity as much as in the gas phase for this compound.

As we did for the neutral compounds, we can estimate the effect of solvation on the protonated compounds by comparing the weights of structures $\mathbf{1}_{\mathbf{P}}$ and $\mathbf{2}_{\mathbf{P}}$ in Table II (solvated phase) to the weights of the same structures in Table I (gas phase). It is seen that the weight of the carbenic form $2_{\mathrm{P}}$ is always larger in solvated phase than in the gas phase, for the three compounds. However, the increase of weight $2_{\mathbf{P}}$ due to solvation $\left(\left(\omega_{2 p}^{\text {solution }} / \omega_{2 p}^{\text {gas }}\right.\right.$ phase $-1) \times 100)$ is significant only for formaldehyde $(+18 \%)$ and thioformaldehyde $(+39 \%)$, but almost negligible, less than $6 \%$, for formimine. Thus, the results for formaldehyde and thioformaldehyde contradict some of the conclusions of our previous study [11], claiming that solvation effects on the weights of the VB structures were weak for all three compounds. This former conclusion, which was based on the use of a crude solvation model, is only valid for the formimine case.

The above analysis has been performed in terms of the purely covalent VB structures $\mathbf{1}$ and $\mathbf{1}_{\mathbf{P}}$, and the carbenic forms 2 and $\mathbf{2}_{\mathrm{P}}$, which are all welldefined in the framework of VB theory. Now chemists rarely consider purely covalent bonds in the case of polar molecules and are more familiar with the concept of polar covalent bond, which however need to be rigorously defined. In our previous study, the $\pi$ polar covalent bond was defined as the $\pi$ bond of the neutral compound $\mathrm{H}_{2} \mathrm{C}=\mathrm{X}$ in the gas phase. Accordingly, the polar covalent structure I in Scheme 1 for the protonated species was defined as having exactly the same polarity as the neutral compound. Extending this definition to the solvated phase, let us define structure I of a protonated species in any phase as a VB structure displaying a polar $\pi$ bond identical to that of the unprotonated species $\mathrm{H}_{2} \mathrm{C}=\mathrm{X}$ in the gas phase (e.g., $68 \%$ covalent and $32 \%$ ionic in the $\mathrm{H}_{2} \mathrm{C}=\mathrm{O}$ case). Thus, the weight of $\mathbf{I}, \omega(\mathbf{I})$, measures that part in the $\pi$ bond of $\left[\mathrm{H}_{2} \mathrm{CXH}\right]^{+}$that is unchanged relative to the neutral species $\mathrm{H}_{2} \mathrm{C}=\mathrm{X}$ in the gas phase. This is readily estimated through Eq. (5):

$$
\begin{array}{r}
\omega(\mathbf{I} \text {, any phase })=\omega\left(\mathbf{1}_{\mathbf{p}} \text {, any phase }\right) / \\
\omega(\mathbf{1}, \text { gas phase })
\end{array}
$$

where $\omega(\mathbf{I}), \omega\left(\mathbf{1}_{\mathbf{P}}\right)$, and $\omega(\mathbf{1})$ refer to the weights of structures $\mathbf{I}, \mathbf{1}$, and $\mathbf{1}_{\mathbf{P}}$, respectively. With this definition, the contribution of II to the resonating Scheme 1 is simply the complement of $\omega(\mathbf{I})$ to unity, and represents the extra carbenic character that is brought by protonation and/or solvation, according to the classical Scheme 1.

The results of this analysis are displayed in Table III. In the gas phase, it appears that the $\pi$ bond in protonated formaldehyde can be viewed as a combination of $72 \%$ of polar-covalent $\pi$ bond, unchanged relative to formaldehyde, and $28 \%$ of carbenium structure. Protonated formimine and thioformaldehyde also exhibit a significant, albeit smaller, contribution of the ionic resonance structure II (19\%). For each compound, the increase of the carbenium structure weight $(\omega($ II)) from gas phase to solution, quantifies the polarity enhancement of protonated compounds due to solvent effect. The weight of structure II is considerably enhanced in solvated phase for protonated formaldehyde and thioformaldehyde, amounting to $42 \%$ and $39 \%$ respectively. On the other hand, solvation

TABLE III

Weights (in \%) of the polar covalent form I vs carbenic form II for protonated formaldehyde, formimine, thioformaldehyde, in gas phase and solvated phase.

\begin{tabular}{lccc}
\hline & $\mathrm{H}_{2} \mathrm{C}=\begin{array}{l}\mathrm{O}^{+} \mathrm{H}_{2} \mathrm{H}_{2} \mathrm{C}^{+}-\mathrm{OH} \\
\omega(\mathrm{I}) / \omega(\mathrm{II})\end{array}$ & $\begin{array}{c}\mathrm{H}_{2} \mathrm{C}=\mathrm{N}^{+} \mathrm{H}_{2} / \mathrm{H}_{2} \mathrm{C}^{+}-\mathrm{NH}_{2} \\
\omega(\mathrm{I}) / \omega(\mathrm{II})\end{array}$ & $\begin{array}{c}\mathrm{H}_{2} \mathrm{C}=\mathrm{S}^{+} \mathrm{H} / \mathrm{H}_{2} \mathrm{C}^{+}-\mathrm{SH} \\
\omega(\mathrm{I}) / /(\mathrm{II})\end{array}$ \\
\hline Gas phase & $71.8 / 28.2$ & $80.8 / 19.2$ & $81.2 / 18.8$ \\
Water phase & $58.4 / 41.6$ & $77.7 / 22.3$ & $61.3 / 38.7$ \\
\hline
\end{tabular}


does not significantly affect the electronic structure of protonated formimine, in which the contribution of the carbonic form amounts to $22 \%$, hardly changed relative to the gas phase.

\section{Conclusion}

The above valence bond calculations show that the traditional resonance model (Scheme 1) for the protonated formalehyde, formimine, and thioformaldehyde is well founded, and this conclusion holds in the gas phase as well as in water phase. In agreement with this model, the calculations show that the electronic structure of the protonated species is a resonating combination of $\mathbf{I}$, displaying a polar $\pi$ bond analogous to that of the unprotonated compound, and the carbenic form II, displaying a pure carbenium character. Solvation by a protic solvent like water further reinforces the participation of the carbenic form II in the cases of formaldehyde and thioformaldehyde, but hardly changes the electronic structure of formimine relative to the gas phase. This finding is in agreement with the net charges that are found at the carbon site in the neutral compounds, very small in the formimine case, and significantly positive in formaldehyde and thioformaldehyde. Generalizing, one might tentatively predict that the conventional resonance model of Scheme 1 is valid for all carbonyl, imine and thiocarbonyl compounds in solvated phase, and that for carbonyl and thiocarbonyl solvation effects further increase the participation of the carbenic form when the carbon atom bears a significant positive net charge.

\section{ACKNOWLEDGMENTS}

The authors are grateful to Professor W. Wu for making the latest version of the XMVB valence bond program so efficient, and also for making it available to us. Benoît Braïda thanks Valentina Vetere for having suggested this work during the last Chitel08, as well as Etienne Derat for the helpful comments and suggestions.

\section{References}

1. Fleming, I. Frontier Orbitals and Organic Chemical Reactions; Wiley: New York, 1976.
2. Olah, G. A.; Laali, K. K.; Prakash, G. K. S. Carboxonium, Carbosulfonium and Carbazonium Ions from Onium Ions; Wiley: New York, N. Y., 1998.

3. Olah, G. A.; White, A. M.; O'Brien, D. H. Chem Rev 1970, 70, 561.

4. Olah, G. A.; Burrichter, A.; Rasul, G.; Gnann, R.; Christe, K. O.; Prakash, G. K. S. J Am Chem Soc 1997, 119, 8035.

5. Olah, G. A.; Berrier, A. L.; Prakash, G. K. S. J Am Chem Soc 1982, 104, 2373.

6. Suarez, D.; Sordo, T. L. J Phys Chem A 1997, 101, 1561.

7. Del Bene, J. E. J Am Chem Soc 1978, 100, 1673.

8. Grana, A. M.; Mosquera, R. A. Chem Phys 1999, 243, 17.

9. Mandado, M.; Van Alsenoy, C.; Mosquera, R. A. J Phys Chem A 2004, 108, 7050.

10. Alkorta, I.; Picazo, O. ARKIVOC; Gainesville, FL, United States, 2005; p 305.

11. Braida, B.; Bundhoo, D.; Engels, B.; Hiberty, P. C. Org Lett 2008, 10, 1951.

12. (a) Miertus, S.; Scrocco, E.; Tomasi, J. Chem Phys 1981, 55, 117; (b) Tomasi, J.; Persico, M. Chem Rev 1994, 94, 2027; (c) Cammi, R.; Tomasi, J. J Comput Chem 1995, 16, 1449.

13. Cossi, M.; Rega, N.; Scalmani, G.; Barone, V. J Comp Chem 2003, 24, 669.

14. Shaik, S.; Hiberty, P. C. Rev Comp Chem 2004, 20, 1.

15. Shaik, S.; Hiberty, P. C. A Chemist's Guide to Valence Bond Theory; Wiley-Interscience: New York, 2007.

16. (a) Hiberty, P. C.; Flament, J. P.; Noizet, E. Chem Phys Lett 1992, 189, 259; (b) Hiberty, P. C.; Humbel, S.; Byrman, C. P.; van Lenthe, J. H. J Chem Phys 1994, 101, 5969; (c) Hiberty, P. C.; Shaik, S. Theor Chem Acc 2002, 108, 255.

17. Chirgwin, H. B.; Coulson, C. A. Proc R Soc Ser A 1950, 2, 196.

18. (a) Harding, L. B.; Goddard, W. A. J Am Chem Soc 1975, 97, 6293; (b) Harding, L. B.; Goddard, W. A. J Am Chem Soc 1975, 97, 6300.

19. (a) Song, L.; Wu, W.; Mo, Y.; Zhang, Q. XMVB: An Ab Initio Nonorthogonal Valence Bond Program; Xiamen University: Xiamen, 1999; (b) Song, L.; Mo, Y.; Zhang, Q.; Wu, W. J Comput Chem 2005, 26, 514.

20. Frisch, M. J.; Trucks, G. W.; Schlegel, H. B.; Scuseria, G. E.; Robb, M. A.; Cheeseman, J. R.; Montgomery, J. A., Jr.; Vreven, T.; Kudin, K. N.; Burant, J. C.; Millam, J. M.; Iyengar, S. S.; Tomasi, J.; Barone, V.; Mennucci, B.; Cossi, M.; Scalmani, G.; Rega, N.; Petersson, G. A.; Nakatsuji, H.; Hada, M.; Ehara, M.; Toyota, K.; Fukuda, R.; Hasegawa, J.; Ishida, M.; Nakajima, T.; Honda, Y.; Kitao, O.; Nakai, H.; Klene, M.; Li, X.; Knox, J. E.; Hratchian, H. P.; Cross, J. B.; Bakken, V.; Adamo, C.; Jaramillo, J.; Gomperts, R.; Stratmann, R. E.; Yazyev, O.; Austin, A. J.; Cammi, R.; Pomelli, C.; Ochterski, J. W.; Ayala, P. Y.; Morokuma, K.; Voth, G. A.; Salvador, P.; Dannenberg, J. J.; Zakrzewski, V. G.; Dapprich, S.; Daniels, A. D.; Strain, M. C.; Farkas, O.; Malick, D. K.; Rabuck, A. D.; Raghavachari, K.; Foresman, J. B.; Ortiz, J. V.; Cui, Q.; Baboul, A. G.; Clifford, S.; Cioslowski, J.; Stefanov, B. B.; Liu, G.; Liashenko, A.; Piskorz, P.; Komaromi, I.; Martin, R. L.; Fox, D. J.; Keith, T.; Al-Laham, M. A.; Peng, C. Y.; Nanayakkara, A.; Challacombe, M.; Gill, P. M. W.; Johnson, B.; Chen, W.; Wong, M. W.; Gonzalez, C.; Pople, J. A. Gaussian 03, Revision C. 02; Gaussian, Inc.: Wallingford CT, 2004. 